\title{
Effect of Whole-abdominal Irradiation on Penetration Depth of Doxorubicin in Normal Tissue After Pressurized Intraperitoneal Aerosol Chemotherapy (PIPAC) in a Post-mortem Swine Model
}

\author{
VERIA KHOSRAWIPOUR ${ }^{1}$, TANJA KHOSRAWIPOUR ${ }^{2}$, YOUSEF HEDAYAT-POUR ${ }^{3}$, DAVID DIAZ-CARBALLO ${ }^{4}$, \\ ALEXANDER BELLENDORF ${ }^{5}$, HUGO BÖSE-RIBEIRO $^{3}$, RALPH MÜCKE $^{3}$, \\ NIRUSHIKA MOHANARAJA ${ }^{1}$, IRENÄUS ANTON ADAMIETZ ${ }^{3}$ and KHASHAYAR FAKHRIAN ${ }^{3}$ \\ ${ }^{1}$ Department of Neuroanatomy, Ruhr University, Bochum, Germany; \\ Departments of ${ }^{2}$ General Surgery, ${ }^{3}$ Radiation Oncology, and \\ ${ }^{4}$ Hematology \& Medical Oncology, Marien Hospital Herne, Ruhr University, Bochum, Germany; \\ ${ }^{5}$ Department of Nuclear Medicine, University Clinic Essen, Essen, Germany
}

\begin{abstract}
Background: This study was performed to evaluate the impact of whole-abdominal irradiation on local penetration of doxorubicin into the peritoneum and the abdominal organs in a post-mortem swine model. Materials and Methods: Doxorubicin was aerosolized into the abdominal cavity of swine at a pressure of $12 \mathrm{mmHg} \mathrm{CO}_{2}$ at room temperature $\left(25^{\circ}\right)$. One swine was subjected to pressurized intraperitoneal aerosol chemotherapy (PIPAC) using Micropump ${ }^{(}$without irradiation; the second one received $2 G y$ and the third one 7 Gy whole-abdominal irradiation, 15 min prior to PIPAC application. Samples of the peritoneal surface were extracted at different positions from within the abdominal cavity. In-tissue doxorubicin penetration was measured using fluorescence microscopy on frozen thin sections. Results: The depth of penetration of doxorubicin was found to be wide-ranging, between $17 \mu \mathrm{m}$ on the surface of the stomach and $348 \mu \mathrm{m}$ in the small intestine. The penetration depth into the small intestine was $348 \mu \mathrm{m}, 312 \mu \mathrm{m}$ and $265 \mu \mathrm{m}$ for PIPAC alone, PIPAC with 2 Gy irradiation and PIPAC with 7 Gy irradiation, respectively $(p<0.05)$. The penetration into the liver was $64 \mu \mathrm{m}, 55 \mu \mathrm{m}$ and $40 \mu \mathrm{m}$, respectively $(p=0.05)$. Conclusion: Irradiation was not found to increase the depth of doxorubicin penetration into normal tissue in the postmortem swine model. A reduction of doxorubicin penetration
\end{abstract}

Correspondence to: Khashayar Fakhrian, MD, Department of Radiation Oncology, Marien Hospital Herne, Ruhr University Bochum, Hölkeskampring 40, 44625 Herne, Germany. Tel: + 49 023234991531, Fax: +49 023234993306, e-mail: khfmed@yahoo.com

Key Words: Post-mortem swine model, whole-abdominal radiation, intraperitoneal chemotherapy, PIPAC, peritoneal carcinomatosis. was observed after application of higher irradiation doses. Further studies are warranted to determine if irradiation can be used safely as chemopotentiating agent for patients with peritoneal metastases treated with PIPAC.

Peritoneal carcinomatosis (PC) is a manifestation of advanced digestive-tract and gynecological cancer $(1,2)$. New approaches are necessary to improve the outcomes of patients with PC. Aerosolized chemotherapeutic applications such as pressurized intraperitoneal aerosol chemotherapy (PIPAC) are assumed to have superior qualities in comparison to liquid intraperitoneal chemotherapy applied with conventional catheters $(3,4)$ and show promising clinical results (5-7). Chemotherapeutic penetration depth into tumoral and peritoneal tissue is reported to be 300 to $600 \mu \mathrm{m}$ with high tissue concentrations observed (0.03-4.1 $\mu \mathrm{mol} / \mathrm{g})$, far higher than previously reported in studies analyzing intraperitoneal chemotherapy $(0.03 \mu \mathrm{mol} / \mathrm{g})(8-10)$. However, despite improvements in the results of the treatment after PIPAC, the outcomes of patients with PC remain poor. There are several reports indicating the synergistic effect of radiation and cytostatics in the treatment of different malignancies $(11,12)$. The additional use of radiation might enhance tumor toxicity by chemosensitizing tumor cells in the peritoneum. However, if irradiation increases the depth of penetration of doxorubicin into normal tissue, collateral toxicity after PIPAC might also be expected. We recently demonstrated in an ex vivo model that irradiation does not increase doxorubicin penetration into normal tissue (13). However, the effect of irradiation on local penetration by doxorubicin after PIPAC has not been studied as far as we are aware in an anatomical model. This study was, therefore, performed to determine the impact of whole-abdominal irradiation on the depth of doxorubicin penetration into the peritoneal layers and abdominal organs after PIPAC in a post-mortem swine model. 


\section{Materials and Methods}

Experiments were performed using three post-mortem swine 30 minutes after death. One swine received whole-abdominal radiation with $2 \mathrm{~Gy}$ and another swine received whole-abdominal radiation with $7 \mathrm{~Gy}$ with $6 \mathrm{mV}$ of photon energy using an Elekta Synergy accelerator (Elekta Synergy ${ }^{\circledR}$; Elekta AB, Stockholm, Sweden).

The animals were then placed in a stable supine position and fixed at all four extremities. An infra-umbilical mini-laparotomy was performed, and a $12 \mathrm{~mm}$ trocar (Kii ${ }^{\circledR}$ Balloon Blunt Tip System; Applied Medical, Rancho Santa Margarita, CA, USA) was inserted into the abdominal cavity (Figure 1). A constant capnoperitoneum was maintained throughout the entire PIPAC experiment (Olympus UHI-3 insufflator; Olympus Medical Life Science and Industrial Divisions, Olympus, Notting Hill, Australia). A $5 \mathrm{~mm}$ camera (Karl Storz GmbH \& Co. KG, Tuttlingen, Germany) was introduced into the $12 \mathrm{~mm}$ trocar. A 5-mm trocar $\left(\mathrm{Kii}^{\circledR}\right.$ Balloon Blunt Tip System; Applied Medical) was then placed under visual control in the right lateral hemiabdomen. A micropump (MIP ${ }^{\circledR}$; Reger Medizintechnik, Rottweil, Germany) was connected to a high-pressure injection line (High Pressure Injection Line with Male/Female Luer lock 120 cm, 1,200 psi; Smith Medical, Hranice, Czech Republic). Doxorubicin (Teva ${ }^{\circledR}$, $2 \mathrm{mg} / \mathrm{ml}$; Pharmachemie B.V., Haarlem, the Netherlands) was drawn into a sterile syringe ( $3 \mathrm{mg}$ in $50 \mathrm{ml}$ of $0.9 \% \mathrm{NaCl}$ ). The syringe was then tightly connected to the high-pressure line and finally brought into the injector head of the high-pressure injector (Injektron $82 \mathrm{M}$; MedTron, Saarbrücken, Germany). The MIP ${ }^{\circledR}$ was inserted into the 12 $\mathrm{mm}$ trocar in a perpendicular position with a maximum distance (8$10 \mathrm{~cm}$ ) of the MIP ${ }^{\circledR}$ nozzle orifice to the serosal surface of the small bowel. The camera was placed and fixed in the $5 \mathrm{~mm}$ trocar to monitor adequate nebulization of the MIP ${ }^{\circledR}$. After the tightness of the abdominal cavity (no $\mathrm{CO}_{2}$ flow) was confirmed, PIPAC was delivered at $25^{\circ} \mathrm{C}$ with a flow rate of $30 \mathrm{ml} / \mathrm{min}$ into the abdominal cavity with a constant capnoperitoneum of $12 \mathrm{mmHg}$. The abdominal cavity was exposed to the doxorubicin aerosol for another $30 \mathrm{~min}$ following the injection phase. The capnoperitoneum was then evacuated via a highefficiency particulate arrestance filter system. Thirty minutes after PIPAC, a laparotomy was performed to retrieve the samples. Peritoneal tissue samples $(1.5 \times 1.5 \times 0.5 \mathrm{~cm})$ were retrieved from the following areas: right upper abdomen, epigastric area, liver, left subdiaphragmal area, left upper abdomen, left lower abdomen, right lower abdomen, stomach, small intestine.

Microscopic analysis. Following treatment, all tissue samples were rinsed with sterile $0.9 \% \mathrm{NaCl}$ solution in order to eliminate superficial cytostatic and immediately frozen in liquid nitrogen. Representative cryo-sections $(7 \mu \mathrm{m})$ were prepared from the nine different areas of specimen collection. Sections were mounted with VectaShield containing $1.5 \mu \mathrm{g} / \mathrm{ml}$ 4',6-diamidino-2-phenylindole to stain nuclei. The depth of doxorubicin penetration was determined using a Leica TCS SP8 confocal laser (Leica Mikrosysteme GmbH, Wetzlar, Hessen, Germany) scanning microscope at $488 \mathrm{~nm}$. The distance between the luminal surface and the innermost positively stained tissue for doxorubicin accumulation was measured and reported in micrometers.

Ethics. The swine were used and killed for a teaching course at a local training center (Aesculap Academie Bochum) prior to the experiment. Approval of the Local Board on Animal Care was obtained (RUB.DE 20 June 2016).

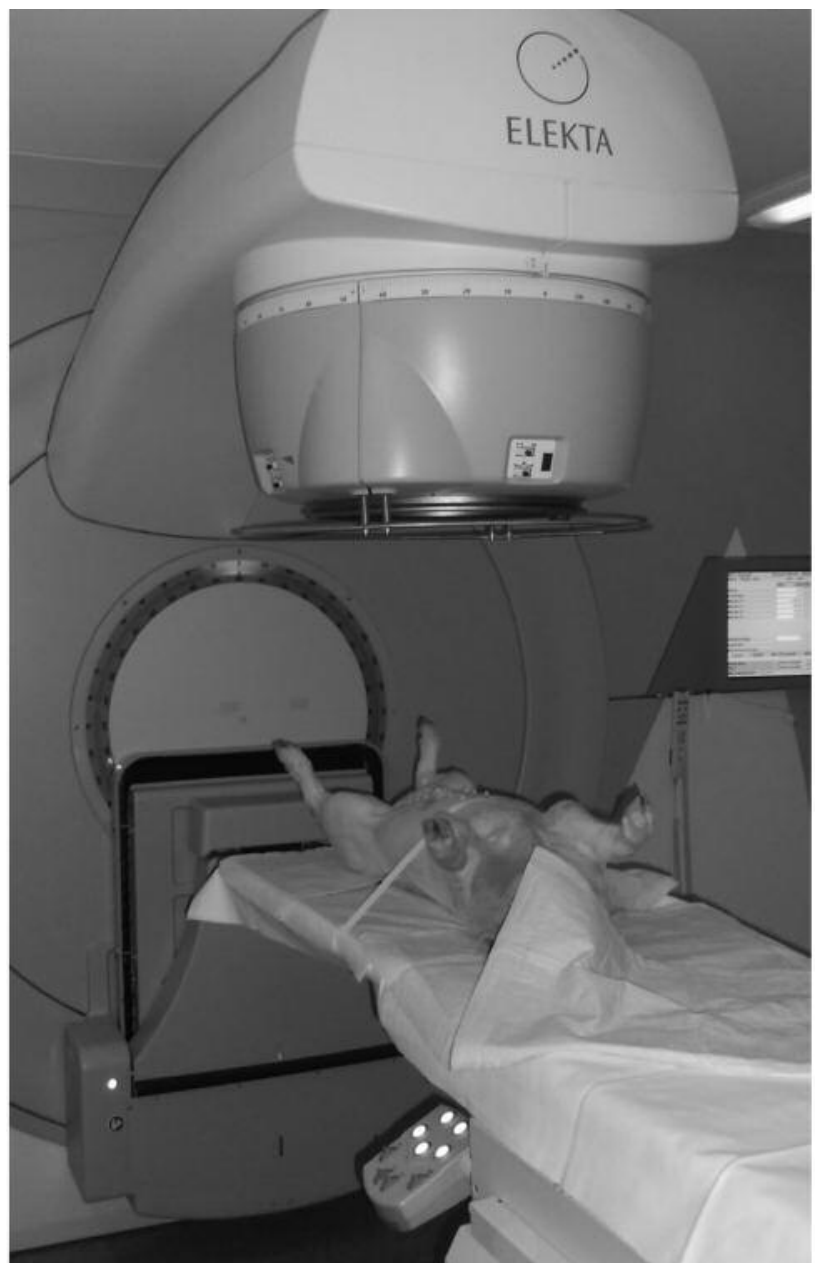

Figure 1. Whole-abdominal irradiation of a fresh post-mortem swine.

\section{Results}

The mean depth of penetration of doxorubicin ranged between $17 \mu \mathrm{m}$ on the surface of the stomach to $348 \mu \mathrm{m}$ in the small intestine. The maximum doxorubicin penetration was in the small intestine just to the MIP (348 $\mu \mathrm{m})$. Irradiation did not lead to a remarkable change in the pattern of doxorubicin penetration into normal tissue. The small intestine and the right upper abdominal peritoneum were the only regions in which irradiation led to a significantly reduced depth of doxorubicin penetration $(p<0.05)$. Detailed depth of doxorubicin penetration into the analyzed regions and the impact of irradiation are demonstrated in Table I.

\section{Discussion}

In spite of intensive research into chemotherapeutic regimes, poor response to systemic treatment is observed in a 

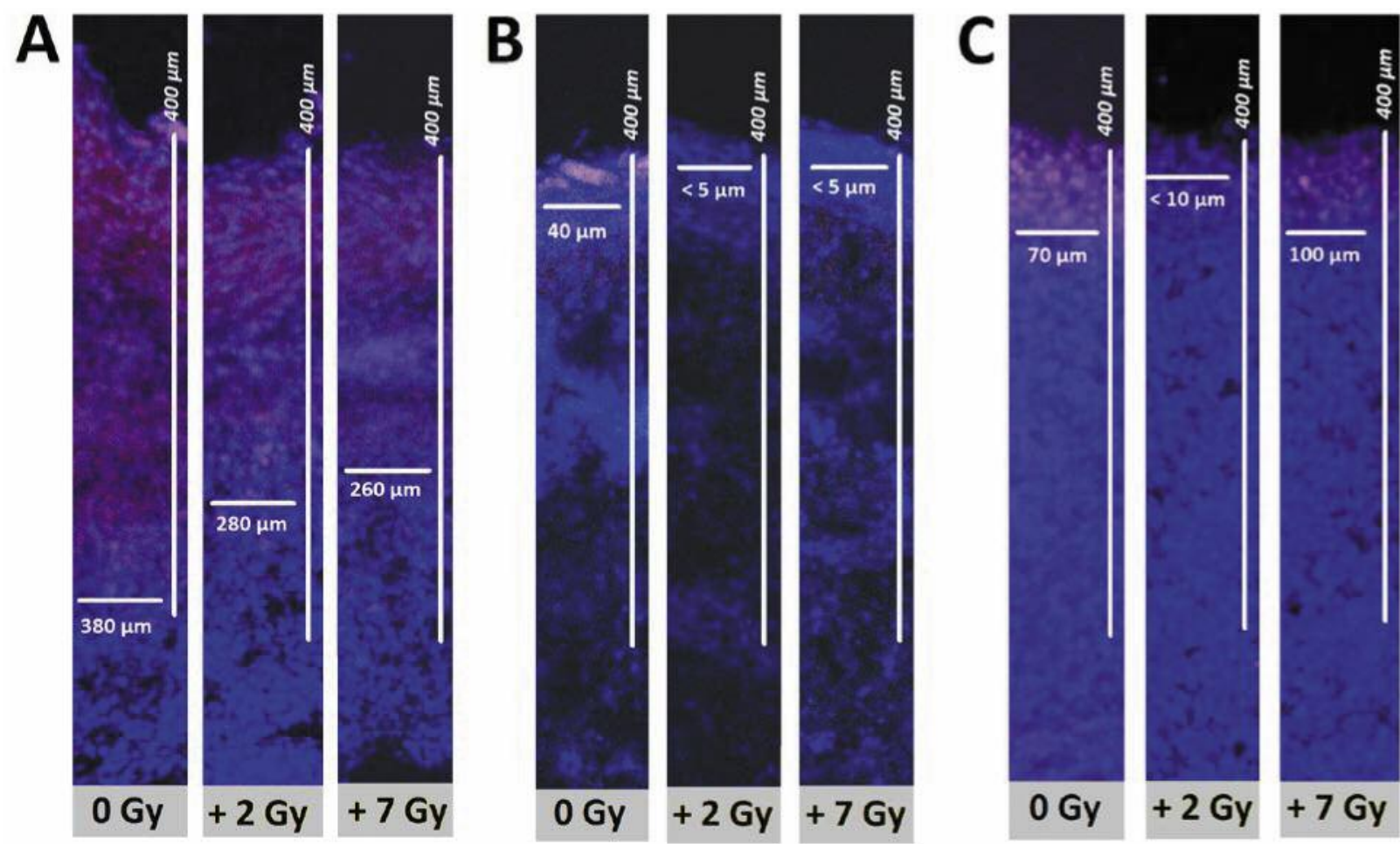

Figure 2. Microscopic analysis of penetration by doxorubicin into samples of small intestine (A), stomach (B) and liver (C) from German Landrace pigs after pressurized intraperitoneal aerosol chemotherapy with and without irradiation. Nuclei (blue) were stained with 4',6-diamidino-2phenylindole.

Table I. Doxorubicin penetration $(\mu m)$ into normal tissue after pressurized intraperitoneal aerosol chemotherapy (PIPAC) with and without irradiation. Data are the mean $\pm S D$.

\begin{tabular}{lcccc}
\hline Tissue site & $\begin{array}{c}\text { PIPAC } \\
\text { without } \\
\text { radiation }\end{array}$ & $\begin{array}{c}\text { PIPAC } \\
\text { with } \\
2 \text { Gy }\end{array}$ & $\begin{array}{c}\text { PIPAC } \\
\text { with } \\
7 \text { Gy }\end{array}$ & $p$-Value \\
\hline Right upper abdomen & $116( \pm 28)$ & $120( \pm 27)$ & $93( \pm 21)$ & $>0.05$ \\
Epigastric area & $41( \pm 25)$ & $23( \pm 25)$ & $64( \pm 16)$ & $>0.05$ \\
Liver & $64( \pm 20)$ & $55( \pm 31)$ & $40( \pm 23)$ & $>0.05$ \\
Left subdiaphragmal area & $83( \pm 24)$ & $37( \pm 26)$ & $72( \pm 25)$ & $>0.05$ \\
Left upper abdomen & $140( \pm 28)$ & $104( \pm 33)$ & $117( \pm 29)$ & $>0.05$ \\
Left lower abdomen & $39( \pm 27)$ & $76( \pm 26)$ & $55( \pm 22)$ & $>0.05$ \\
Right lower abdomen & $100( \pm 32)$ & $86( \pm 33)$ & $32( \pm 18)$ & $<0.05$ \\
Stomach & $23( \pm 14)$ & $47( \pm 29)$ & $31( \pm 17)$ & $>0.05$ \\
Small intestine & $349( \pm 40)$ & $330( \pm 49)$ & $265( \pm 33)$ & $<0.05$ \\
\hline
\end{tabular}

considerable proportion of patients $(1,2,4)$. The novel PIPAC approach has shown promising clinical results in patients with PC (5-7), but optimization of treatment is necessary. Combined radiotherapy and intra-abdominal chemotherapy might achieve more efficient tumor elimination. However, increased toxicity through a higher drug uptake in normal tissue is of great concern. To our knowledge, there are no data about radiotherapy prior to or after intraperitoneal chemotherapy. We previously demonstrated that higher doses of irradiation might reduce the depth of penetration of doxorubicin in isolated tissue samples from the peritoneum (14). However, the biological mechanisms underlying principles of the observed and radiation-induced changes are currently unclear. Our results indicate that a radiation dose of 2 or $7 \mathrm{~Gy}$ did not appear to increase drug penetration into normal tissue in this ex vivo swine model.

Penetration depth for each swine varied to some degree. In particular, the small intestine and the upper abdomen showed high degrees of penetration. This indicates an inhomogenous drug distribution pattern after PIPAC, which is in line with our previous findings (15-17). Furthermore, it should be noted that the area around and opposite the MIP is exposed to the maximal concentration of the drug for a longer time. In fact, the concentration of the aerosol drug might be lower at distant areas due to its dilution by normal intraperitoneal fluid during the procedure. An important limitation of our study resides in the fact that our experiments were performed in a post-mortem model. Although the peritoneum is not a organ that suffers shock 
like the heart, brain or liver, its response to PIPAC may differ in a living organism with regular blood circulation. However, the results of this study help to stablish the foundation for further studies using in vivo models.

\section{Conclusion}

Irradiation did not increase the depth of doxorubicin penetration into normal tissue of the post-mortem swine model. The highest penetration was measured in the small intestine around the MIP. Doxorubicin penetration into normal tissue was reduced after application of higher irradiation doses. Further studies are warranted to determine if irradiation can be used safely as chemopotentiating agent for patients with peritoneal metastases treated with PIPAC.

\section{Disclosure}

This study was funded by institutional funds. The Authors have no conflicts of interest.

\section{References}

1 Sadeghi M, Arvieux C, Glehen O, Beaujard AC, Rivoire M, Baulieux J, Fontaumard E, Brachet A, Caillot JL, FaureJL, Porcheron J, Peix JL, Francois Y, Vignal J and Gilly N: Peritoneal carcinomatosis from non-gynecological malignancies: Results of the EVOCAPE 1 multicentric prospective study. Cancer 88(2): 358-363, 2000.

2 Sugarbaker PH: Peritoneal carcinomatosis: Is cure an option? J Clin Oncol 21(5): 762-764, 2003.

3 Chua TC, Esquivel J, Pelz JO and Morris DL: Summary of current therapeutic options for peritoneal metastases from colorectal cancer. J Surg Oncol 107(6): 566-573, 2013.

4 Al-Quteimat $\mathrm{OM}$ and Al-Badaineh MA: Intraperitoneal chemotherapy: rationale, applications, and limitations. J Oncol Pharm Pract 20(5): 369-380, 2014

5 Tempfer CB, Rezniczek GA, Ende P, Solass W and Reymond MA: Pressurized intraperitoneal aerosol chemotherapy with cisplatin and doxorubicin in women with peritoneal carcinomatosis: a cohort study. Anticancer Res 35(12): 6723-6729, 2015.

6 Nadiradze G, Giger-Pabst U and Zieren J, Strumberg D, Solass $\mathrm{W}$ and Reymond MA: Pressurized intraperitoneal aerosol chemotherapy (PIPAC) with low-dose cisplatin and doxorubicin in gastric peritoneal metastasis. J Gastrointest Surg 20(2): 367373, 2016.

7 Demtröder C, Solass W, Zieren J, Strumberg D, Giger-Pabst U and Reymond MA: Pressurized intraperitoneal aerosol chemotherapy with oxaliplatin in colorectal peritoneal metastasis. Colorectal Dis 18(4): 364-371, 2016.

8 Jacquet P, Stuart OA, Chang D and Sugarbaker PH. Effects of intraabdominal pressure on pharmacokinetics and tissue distribution of doxorubicin after intraperitoneal administration. Anticancer Drugs 7(5): 596-603, 1996.
9 Solaß W; Kerb R, Mürdter T, Giger-Pabst U,Strumber D, Tempfer C, Zieren $\mathrm{J}$ and Schwab M: Intraperitoneal chemotherapy of peritoneal carcinomatosis using pressurized aerosol as an alternative to liquid solution: first evidence for efficacy. Ann Surg Oncol 21(2): 553-559, 2014.

10 Solaß W, Hetzel A, Nadiradze G, Sagynaliev E and Reymond MA: Description of a novel approach for intraperitoneal drug delivery and the related device. Surg Endosc 26(7): 1849-1855, 2012.

11 Rochet N, Lindel K, Katayama S, Schubert K, Herfarth K, Schneeweiss A, Sohn C, Harms W and Debus J: Intensitymodulated whole-abdomen irradiation following adjuvant carboplatin/taxane chemotherapy for FIGO stage III ovarian cancer: four-year outcomes. Strahlenther Onkol 191(7): 582-589, 2015.

12 Wrenn DC, Saigal K, Lucci JA 3rd, Pearson MJ, Simpkins F, Schuman S, Twiggs LB, Walker GR and Wolfson AH: A phase I study using low-dose fractionated whole abdominal radiotherapy as a chemopotentiator to full-dose cisplatin for optimally debulked stage III/IV carcinoma of the endometrium. Gynecol Oncol 122(1): 59-62, 2011.

13 Khosrawipour V, Bellendorf A, Khosrawipour T, Hedayat-Pour Y and Diaz-Carballo Y, Förster E, Mücke R, Kabaci B, Adamietz IA and Fakhrian K: Irradiation does not increase the penetration depth of doxorubicin in normal tissue after pressurized intraperitoneal aerosol chemotherapy (PIPAC) in an ex vivo model. In Vivo 30(5): 593-597, 2016.

14 Khosrawipour V, Giger-Pabst U and Khosrawipour T, Pour YH, Diaz-Carballo D, Förster E, Böse-Ribeiro H, Adamietz IA, Zieren $\mathrm{J}$ and Fakhrian K: Effect of irradiation on tissue penetration depth of doxorubicin after pressurized intraperitoneal aerosol chemotherapy (PIPAC) in a novel ex vivo model. J Cancer 7(8): 910-914, 2016.

15 Khosrawipour V, Khosrawipour T, Diaz-Carballo D and Förster E, Zieren $J$ and Giger-Pabst U: Exploring the spatial drug distribution pattern of pressurized intraperitoneal aerosol chemotherapy (PIPAC). Ann Surg Oncol 23(4): 1220-1224, 2016.

16 Khosrawipour V, Khosrawipour T, Falkenstein TA, DiazCarballo D and Förster E, Osma A, Adamitz IA, Zieren J and Fakhrian K: Evaluating the effect of micropump ${ }^{\odot}$ position, internal pressure and doxorubicin dosage on efficacy of pressurized intra-peritoneal aerosol chemotherapy (PIPAC) in an ex vivo model. Anticancer Res 36(9): 4595-4600, 2016.

17 Khosrawipour V, Khosrawipour T, Kern AJ, Osma A, Kabakci B, Diaz-Carballo D and Förster E, Zieren J and Fakhrian K: Distribution pattern and penetration depth of doxorubicin after pressurized intraperitoneal aerosol chemotherapy (PIPAC) in a postmortem swine model. J Cancer Res Clin Oncol 142(11): 2275-2280, 2016. 